\title{
DETERMINATION OF HEAT LOAD BY WET BULB GLOBE TEMPERATURE IN WORKING ENVIRONMENT
}

\author{
KRÁLIKOVÁ Ružena \\ Faculty of Mechanical Engineering/Department of Process and Environmental Engineering, Technical \\ University of Košice, Košice, Slovakia, ruzena.kralikova@tuke.sk \\ MAD̆ORANOVÁ Marieta \\ Faculty of Mechanical Engineering/Department of Process and Environmental Engineering, Technical \\ University of Košice, Košice, Slovakia, marieta.madoranova@student.tuke.sk
}

\begin{abstract}
Thermal load on people in general depends on the heat production in the human organism as a result of physical activity as well as environmental conditions which are affected by transfer of heat between human and the surrounding area. The resulting effect of metabolic exchanges which occur in work activities is the thermal load of organism. The paper deals with the evaluation of microclimatic conditions of the working environment of workers, who are exposed to the hot environment during their work.
\end{abstract}

Key words: working environment, microclimatic conditions, human, heat load

\section{Introduction}

Stress at workplace usually arises from an interaction of several risk factors. One of them may also be unsuitable climatic conditions. Thermal-moisture microclimate (TMM) is part of the overall microclimate in working environment, in which the most important factors are air temperature, middle temperature of the radiation, air moisture and air velocity.

At workplaces, where the values exceed acceptable microclimatic conditions due to the heat load from technological resources and at the rest of workplaces, where during extraordinary hot days work hours must be adjusted so that long-term and short-term viable TMM conditions are not exceeded. Acceptable microclimatic conditions are identified by long and short term tolerable load of the heat. Viable long-term heat load is limited by the amount of water excreted from the body through sweating and breathing, limit values for acclimated and non-acclimated employees are set out in decree [5]. Shorttolerable heat load is limited by the amount of stored heat in the body, that for acclimatized and nonacclimatized employees must not exceed $180 \mathrm{~kJ} . \mathrm{m}^{-2}$. This corresponds to a rise in core body temperature of $0.8 \mathrm{~K}$, the rise of average skin temperature by $3.5 \mathrm{~K}$ and increase of heart rate to a maximum value of $150 \mathrm{~min}^{-1}$.

Long and short periods of work acceptable at increased load of heat for men and women are determined by dependence on the energy intensity work class and the microclimatic conditions for acclimatized and non-acclimatized workers. Specific situation in the workplace is the thermal load from strong radiation from heat sources. In this case, the heat load for each exposed workplace using appropriate evaluation methods with the help of stereotemperature $t_{\mathrm{g}}$, asymmetry in radiation temperature or by WGBT indicator [3]. In case of radiant heat sources where stereotemperature at workplace exceeds $43^{\circ} \mathrm{C}$ or radiance exceeds $700 \mathrm{~W} \cdot \mathrm{m}^{-2}$, it is necessary to use protection against radiant heat.

\section{Bearable heat load}

From the basic data it is possible to determine heat load by Wet Bulb Globe Temperature (WBGT) indicator by measuring of parameters derived from the data. WBGT is one of empiric indicators representing heat load, to which an individual is exposed [3,4].

It represents a wet and ball thermometer temperatures, which combines natural ventilation temperature of the wet bulb thermometer $t_{\mathrm{vn}}$, the resulting temperature of ball thermometer $t_{\mathrm{g}}$, and air temperature $\mathrm{t}_{\mathrm{a}}$. WBGT indicator without the influence of solar radiation is calculated as:

$$
W B G T=0,7 t_{n v}+0,3 t_{g} \text {. }
$$


For WGBTS indicator with solar radiation applies:

WBGTS $=0,7 t_{n v}+0,2 t_{g}+0,1 t_{a}$.

Evaluation method of heat stress according to this indicator describes the standard STN ISO 7243 "Hot environment: Determination of worker's thermal load ratio according to WBGT indicator" [3].This evaluation method is considered only as a screening method. It is a compromise between the exact evaluation of the heat load and the effort to carry out control measurements in industrial applications.

Direct determination of the heat load by analysing data on heat exchange between men and the environment allows to accurately assess the load and to analyse ways of protection, which is very laborious and time consuming. It requires further detailed analysis and synthesis of data about working conditions in a hot environment and about individuals, especially when the acquired data exceed benchmarks of WGBT (see Table 1).

For reliable classification of the size of energy outgo it is necessary to make an objective measurement of energy outgo according to a detailed analysis of the activity. Reference values correspond to the level of exposure which workers can (under the conditions listed in Table 1) be exposed to without adverse effects on health, and these conditions should not cause accidents, as they were found no contra findings.

The introduction of methods for assessing the heat load by the WGBT indicator replace several methods of determining the heat load, because such indicator does not exist yet. Established international standard is suitable for use in industrial environments [3]. This standard is not suitable for assessing heat load during short time intervals, nor the evaluation of thermal comfort conditions. It is designed to assess the average effect of heat on men during the period of its effect and provides quick information.

Table 1: Reference values of WBGT heatload

\begin{tabular}{|c|c|c|c|c|c|c|}
\hline \multirow[b]{2}{*}{ No. } & \multicolumn{2}{|c|}{ Energetic outgo } & \multicolumn{4}{|c|}{ Reference value of WBGT } \\
\hline & $\mathbf{q}_{M}\left[\mathbf{W} \cdot \mathbf{m}^{-2}\right]$ & $\mathbf{M}[\mathbf{W}]$ & \multicolumn{2}{|c|}{$\begin{array}{l}\text { Person acclimatized } \\
\text { on heat }\left[{ }^{\circ} \mathrm{C}\right]\end{array}$} & \multicolumn{2}{|c|}{$\begin{array}{c}\text { Person not acclimatized } \\
\text { on heat }\left[{ }^{\circ} \mathrm{C}\right]\end{array}$} \\
\hline $\mathbf{0}$ & $\mathrm{M} \leq 65$ & $\mathrm{M} \leq 117$ & \multicolumn{2}{|c|}{33} & \multicolumn{2}{|c|}{32} \\
\hline 1 & $65<\mathrm{M} \leq 130$ & $117<\mathrm{M} \leq 234$ & \multicolumn{2}{|c|}{30} & \multicolumn{2}{|c|}{29} \\
\hline 2 & $130<\mathrm{M} \leq 200$ & $234<\mathrm{M} \leq 360$ & \multicolumn{2}{|c|}{28} & \multicolumn{2}{|c|}{26} \\
\hline \multirow[t]{2}{*}{3} & \multirow[t]{2}{*}{$200<\mathrm{M} \leq 260$} & \multirow[t]{2}{*}{$360<\mathrm{M} \leq 468$} & $\begin{array}{c}\text { No feeling } \\
\text { of air } \\
\text { moving }\end{array}$ & $\begin{array}{l}\text { Feeling of } \\
\text { air moving }\end{array}$ & $\begin{array}{c}\text { No feeling } \\
\text { of air } \\
\text { moving }\end{array}$ & $\begin{array}{l}\text { Feeling of } \\
\text { air moving }\end{array}$ \\
\hline & & & 25 & 26 & 22 & 23 \\
\hline 4 & $\mathrm{M}>260$ & $M>468$ & 23 & 25 & 18 & 20 \\
\hline
\end{tabular}

No. - energetic outgo class` size according to character of work (0 - tranquility, 1 low, 2 - medium,

3 - high, 4 - very high energetic outgo); qM - energetic outgo per body unit [W.m-2]; M total energetic outgo per standard person with body coverage of $1.8 \mathrm{~m} 2$

If reference benchmarks of heat load indicator are exceeded, it is necessary to lower heat load at workplace by appropriate technical measures or by organizational measures - determining the bearable work time. Setting the bearable work time can ensure compliance with viable long-term or short-term heat load. Indicative values of long and short term viable heat load are listed in the Annexes to the Decree [5].

\section{Practical verification of measuring methodology}

TMM has been the subject of measuring small foundry workplace, where a radiant heat sources were four furnaces. Measuring points (M1 to M4) were selected to represent place of residence of workers during the performance of their work. Measurement was carried out during a summer day with daytime temperatures from 18 to $29^{\circ} \mathrm{C}$ in the morning time change.

Measured parameters were air temperature $t_{a}\left({ }^{\circ} \mathrm{C}\right)$, the resulting spherical bulb temperature $t_{\mathrm{g}}\left({ }^{\circ} \mathrm{C}\right)$, wet bulb temperature $\mathrm{t}_{\mathrm{vn}}\left({ }^{\circ} \mathrm{C}\right)$, air velocity $\mathrm{v}_{\mathrm{a}}\left(\mathrm{m} \cdot \mathrm{s}^{-1}\right)$ and relative humidity $\mathrm{R}_{\mathrm{h}}(\%)$. Digital devices with a spherical sensor $t_{g}, t_{v n}$ triple-probe for sensing $v_{a}, R_{h}, t_{a}$ were used.

Basic characteristics of the sample number of measured values (selective average $\bar{x}$, maximum, minimum and standard deviation of selection s) are listed in Table 2 and Table 3. 
Using the scatter chart (Figure 1 - Figure 2) the measured values of the variables at different sites of measurement are shown.

Table 2: Descriptive statistics - Measuring points M1 and M2

\begin{tabular}{|c|c|c|c|c|c|c|c|c|}
\hline & \multicolumn{4}{|c|}{ M1 } & \multicolumn{4}{c|}{ M2 } \\
\cline { 2 - 9 } & $\min$ & $\overline{\boldsymbol{x}}$ & $\mathbf{m a x}$ & $\boldsymbol{s}$ & $\mathbf{m i n}$ & $\overline{\boldsymbol{x}}$ & $\mathbf{m a x}$ & $\boldsymbol{s}$ \\
\hline $\boldsymbol{t}_{\boldsymbol{g}}$ & 36,3 & 36,7667 & 37,0 & 0,3011 & 33,6 & 35,1167 & 35,7 & 0,7935 \\
\hline $\boldsymbol{t}_{\boldsymbol{a}}$ & 33,8 & 34,083 & 34,5 & 0,2483 & 32,8 & 33,450 & 35,4 & 0,9731 \\
\hline $\boldsymbol{t}_{\boldsymbol{v}}$ & 26,5 & 26,6667 & 26,90 & 0,1633 & 25,9 & 26,0333 & 26,30 & 0,1366 \\
\hline $\boldsymbol{v}_{\boldsymbol{a}}$ & 0,10 & 0,1433 & 0,22 & 0,0468 & 0,14 & 0,2350 & 0,32 & 4,2881 \\
\hline $\boldsymbol{R}_{\boldsymbol{h}}$ & 44,0 & 48,000 & 55,3 & 4,2881 & 44,7 & 46,750 & 51,8 & 2,5844 \\
\hline
\end{tabular}

Table 3: Descriptive statistics - Measuring points M3 and M4

\begin{tabular}{|c|c|c|c|c|c|c|c|c|}
\hline & \multicolumn{5}{|c|}{ M3 } & \multicolumn{4}{c|}{ M4 } \\
\cline { 2 - 9 } & $\mathbf{m i n}$ & $\overline{\boldsymbol{x}}$ & $\mathbf{m a x}$ & $\boldsymbol{s}$ & $\mathbf{m i n}$ & $\overline{\boldsymbol{x}}$ & $\mathbf{m a x}$ & $\boldsymbol{s}$ \\
\hline $\boldsymbol{t}_{\boldsymbol{g}}$ & 36,1 & 36,7500 & 37,4 & 0,5541 & 34,9 & 35,3500 & 35,5 & 0,2345 \\
\hline $\boldsymbol{t}_{\boldsymbol{a}}$ & 32,2 & 33,600 & 34,6 & 1,0714 & 33,1 & 33,200 & 33,3 & 0,0894 \\
\hline $\boldsymbol{t}_{\boldsymbol{v}}$ & 26,2 & 26,6333 & 27,00 & 0,3830 & 23,2 & 25,7667 & 26,30 & 1,2580 \\
\hline $\boldsymbol{v}_{\boldsymbol{a}}$ & 0,11 & 0,2067 & 0,28 & 0,0641 & 44,0 & 46,450 & 52,1 & 2,9541 \\
\hline $\boldsymbol{R}_{\boldsymbol{h}}$ & 0,11 & 0,2200 & 0,32 & 0,0807 & 44,2 & 46,117 & 48,2 & 1,3318 \\
\hline
\end{tabular}

Figure 1: a) Resulting temperature of the ball thermometer, b) Air temperature
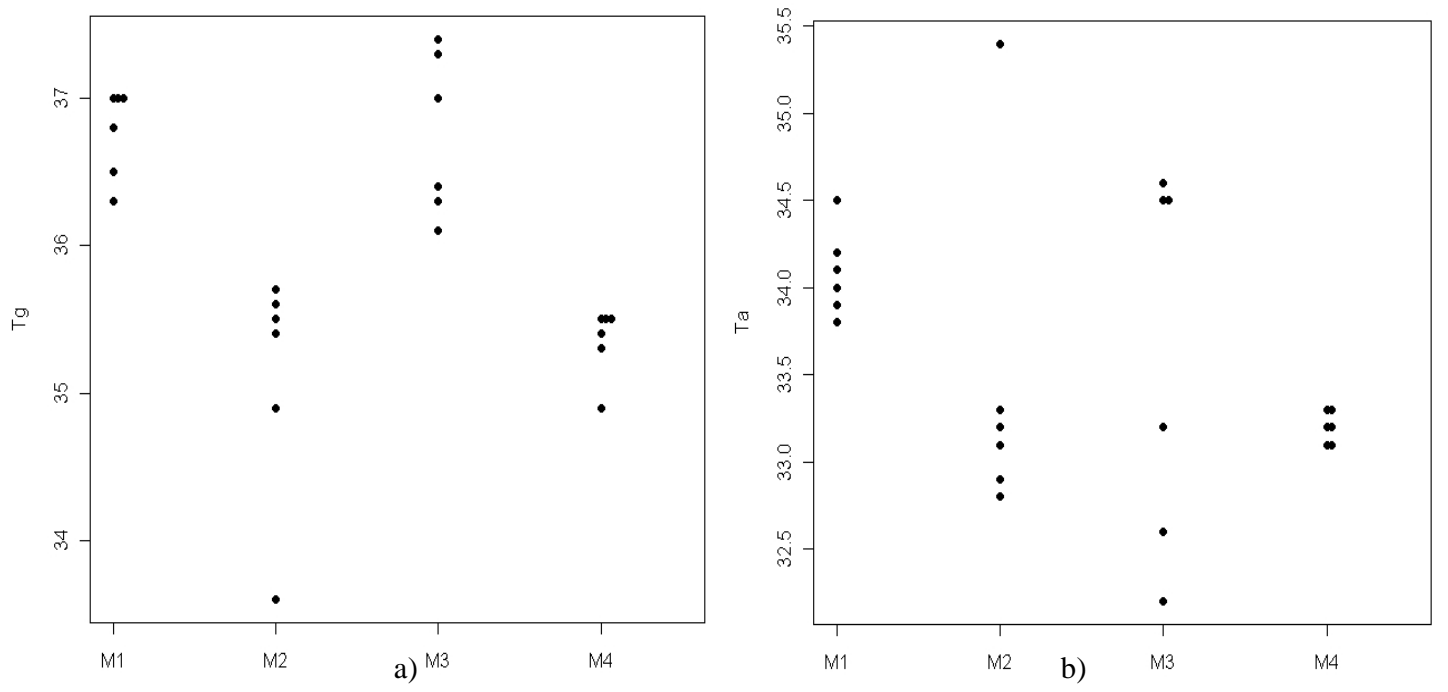

Figure 2: a) Air velocity, b) Relative humidity
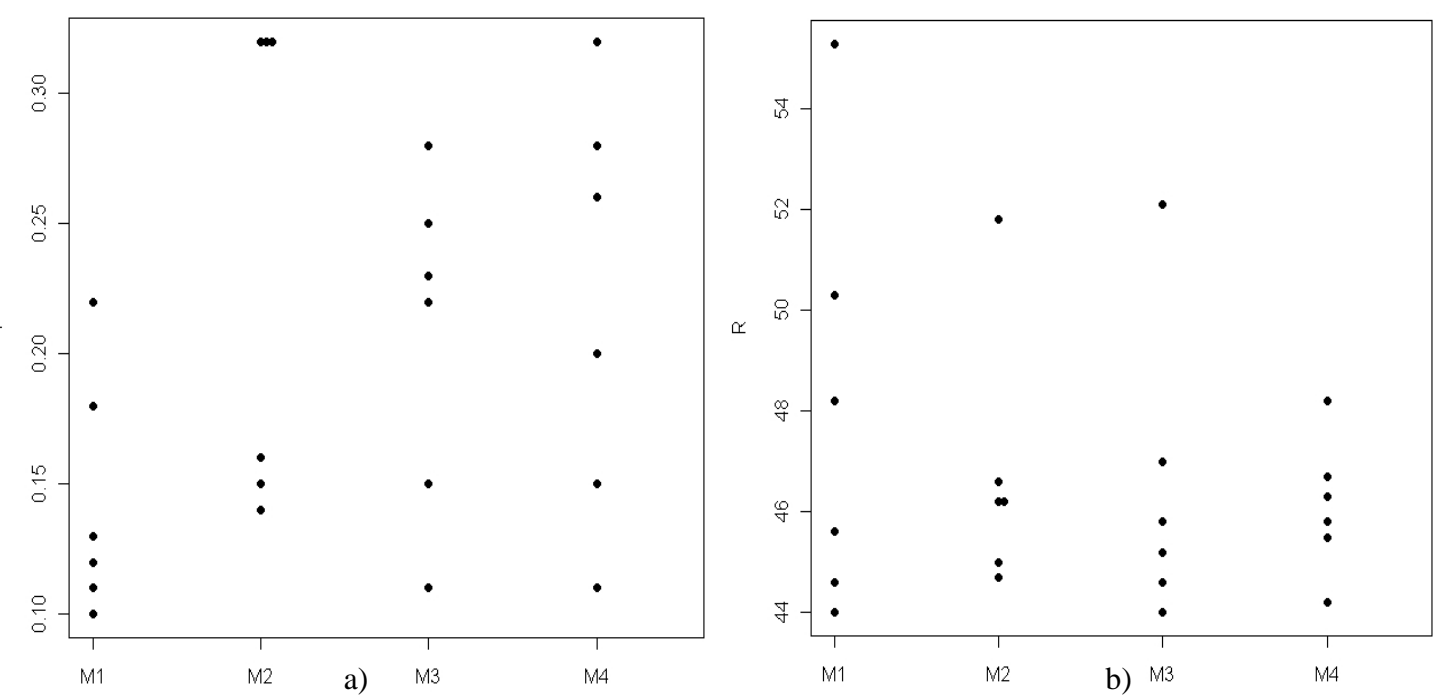
The average median value of radiation temperature $t_{r}\left({ }^{\circ} \mathrm{C}\right)$, operative temperature $t_{0}\left({ }^{\circ} \mathrm{C}\right)$ and the intensity of radiation I (W.m ${ }^{-2}$ ) for each measuring point were obtained by relations (1), (2) and are listed in Table 4. These values significantly exceeded the limit values.

Table 4: Values $-t_{r}, t_{o}, I$

\begin{tabular}{|c|c|c|c|}
\hline $\begin{array}{c}\text { Measuring } \\
\text { place }\end{array}$ & $\boldsymbol{t}_{\boldsymbol{r}}\left[{ }^{\circ} \mathbf{C}\right]$ & $\boldsymbol{t}_{\boldsymbol{o}}\left[{ }^{\circ} \mathbf{C}\right]$ & $\boldsymbol{I}\left[\mathbf{[ W . m ^ { - 2 }}\right]$ \\
\hline M1 & 38,79 & 36,44 & 46,24 \\
\hline M2 & 36,83 & 35,14 & 32,69 \\
\hline M3 & 39,69 & 36,65 & 52,61 \\
\hline M4 & 37,47 & 35,34 & 37,08 \\
\hline
\end{tabular}

Calculated values for WGBT indicator according to equation (2) for the individual measuring points are listed in Table 5. Scatter plots of measured values of wet bulb thermometer temperature and the calculated values of WBGT heat load are shown in Figure 3.

Table 5: WBGT values for measuring points M1, M2, M3, M4

\begin{tabular}{|c|c|c|c|c|}
\hline \multirow{2}{*}{ Time } & \multicolumn{4}{|c|}{ WBGT } \\
\cline { 2 - 5 } & M1 & M2 & M3 & M4 \\
\hline $9: 00$ & 29,73 & 28,88 & 29,47 & 29,03 \\
\hline $10: 00$ & 29,72 & 28,84 & 29,23 & 26,89 \\
\hline $11: 00$ & 29,86 & 28,28 & 29,17 & 28,88 \\
\hline $12: 00$ & 29,72 & 29,03 & 29,93 & 28,93 \\
\hline $13: 00$ & 29,50 & 28,85 & 30,09 & 29,06 \\
\hline $14: 00$ & 29,65 & 28,67 & 30,12 & 29,06 \\
\hline
\end{tabular}

Figure 3: a) Temperature of wet bulb thermometer, b) WBGT indicator
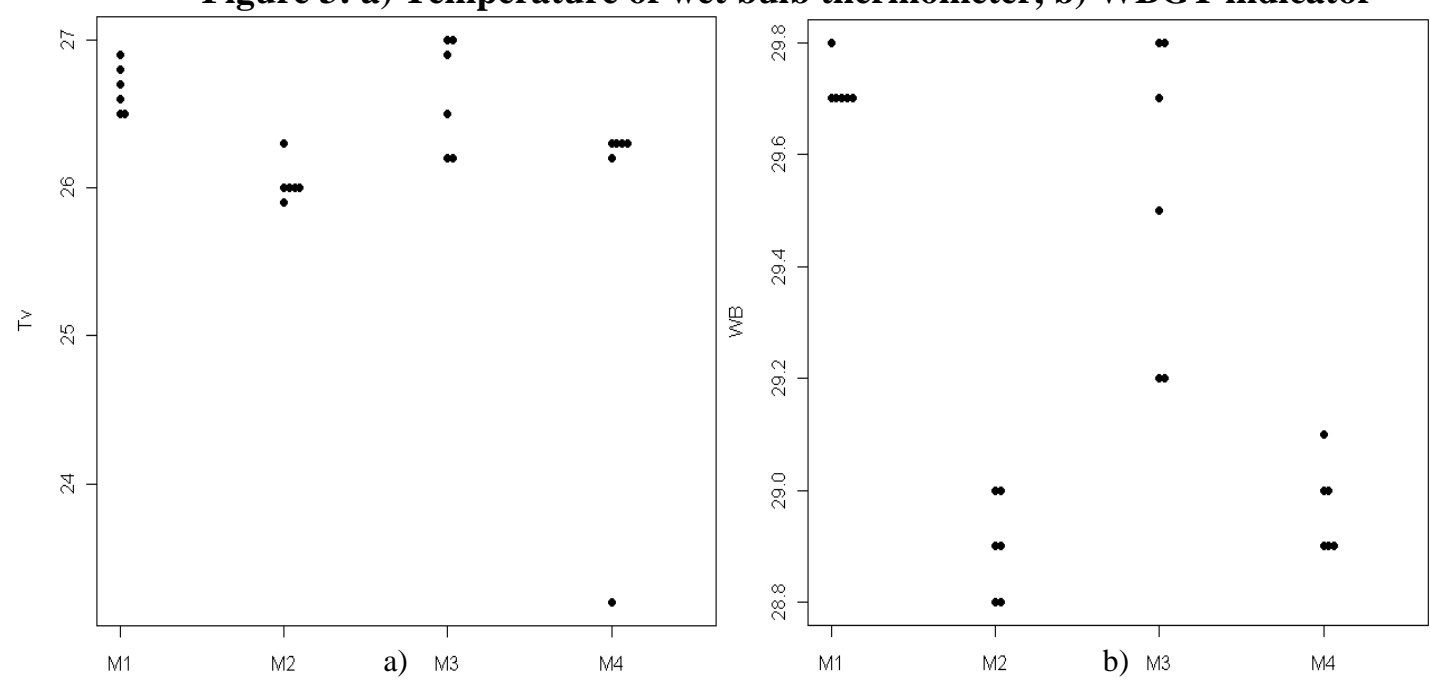

The values of the thermal load indicator by WGBT are compared with benchmark WGBT indicators, which are listed in Table 2. By comparing the values significant differences were found, on these basis it is necessary to draw the appropriate technical, health, organizational and other measures.

\section{Conclusions}

Hot environment weakens the physical and mental performance. If the values of microclimatic variables are beyond the permissible values the work time must be adjusted in order to meet long-and short-term tolerable heat load. The most effective protection against heat load is combination of various methods - technical regulation or administrative regulation, and personal protective equipment (cooling, breathable clothes), water refreshment (hydration), breaks in work time. Acclimatization is another option - it is a result of physiological adaptation process. Acclimatization can be achieved either artificially by controlled repeated exposure in the acclimatization chamber, or naturally by progressive prolongation of intervals of performed work in hot environment. This work was supported by project APVV - 0432-12. 


\section{References}

- Parsons, K., Heat Stress ISO 7243 and its Global Application, Industrial Health, Vol. 44, pp. 368379, (2006).

- ISO 9886, Evaluation of thermal strain by physiological measurements, Geneva: International Standards Organisation, (1992).

- ISO 7243, Hot Environments-Estimation of the heat stress on working man, based on the WBGTindex (wet ulb globe temperature). Geneva: International Standards Organization, (2003).

- ISO 7726, Ergonomics of the thermal environment-Instruments for measuring physical quantities, (2003).

- Decree No. 544/2007: Ministry of Health of The Slovak Republic, which Contains Details on Health Protection Against Heat and Cold Load at Work.

- Ministry of Health Bulletin No 27/49, Vocational guideline Slovak Ministry of Health, which regulates the procedure for the measurement and evaluation of thermal-moisture microclimate, (2013).

- Kralikova, R., Sokolova, H., Wessely, E., Thermal environment evaluation according to indices in industrial workplaces, Procedia Engineering, Vol. 69, pp. 158-167, (2014). 